\title{
Successful vitrification of day-6 sheep embryos
}

\author{
J. Ali* and J. N. Shelton \\ Developmental Physiology Group, Division of Clinical Sciences, John Curtin School of Medical \\ Research, The Australian National University, PO Box 334, Canberra, ACT 2601, Australia
}

\begin{abstract}
The aim of the experiments described here was to investigate cryopreservation of day- 6 sheep embryos by vitrification methods in which the preliminary procedures can be performed at room temperature using VSI (5.5 mol ethylene glycol $\mathrm{l}^{-1}$ and $2.5 \mathrm{~mol}_{\text {glycerol }} \mathrm{l}^{-1}$ ), VSII $\left(6.0 \mathrm{~mol}\right.$ ethylene glycol $\mathrm{l}^{-1}$ and $1.8 \mathrm{~mol}$ glycerol $\left.\mathrm{l}^{-1}\right)$ and VS14 (5.5 mol ethylene glycol $\mathrm{I}^{-1}$ and $1.0 \mathrm{~mol}$ sucrose $\mathrm{l}^{-1}$ ). None of the day-6 sheep embryos vitrified with VSI survived. Day- 6 sheep embryos with the exception of blastocysts were vitrified with VSII with no loss of viability in vitro. The viability of transferred day-6 embryos vitrified with VS11 was however extremely poor. Osmotic damage was avoided by initially exposing the embryos to one of four dilutions (20\%,30\%,40\% and $50 \%$ ) of VSII for $5 \mathrm{~min}$ at $25^{\circ} \mathrm{C}$ and then vitrifying with the undiluted VS11. The highest survival $(88.2 \%)$ in vitro was obtained when embryos were exposed to $30 \%$ VS11 before vitrification with the undiluted VS11. Survival of transferred embryos exposed to $30 \%$ VSII and then vitrified with undiluted VS11 was $55 \%$ ( 16 of 29 ) for morulae and $62 \%$ ( 18 of 29 ) for blastocysts. The pregnancy rate for recipients that received two vitrified sheep embryos of these developmental stages per ewe was $79 \%$ ( 22 of 28 ). In a small study performed with VS14 the survival of day- 6 sheep embryos vitrified with VS14 (in one-step) was $100 \%$ in vitro and $50 \%$ after transfer.
\end{abstract}

\section{Introduction}

There have been two approaches to the cryopreservation of embryos. The first was slow freezing and, after the report of live births from frozen mouse embryos (Whittingham et al., 1972), the technique has been applied to a number of other mammalian species including sheep (Willadsen et al., 1976). The other approach is vitrification, which was first suggested by Luyet (1937), and successfully applied to mouse embryos by Rall (1987). Vitrification eliminates the formation of ice which can be lethal to embryos. An additional advantage of vitrification is that the very rapid freezing rate required to achieve vitrification, at concentrations of cryoprotectants that are not immediately toxic to embryos, can be achieved by plunging them into liquid nitrogen, thus eliminating the need for controlled-rate cooling apparatus. Sheep embryos have proven more sensitive than mouse embryos to the vitrification procedures and only moderate success has been achieved using solutions in which the major permeating cryoprotectants were glycerol and propylene glycol (Szell et al., 1990; Schiewe et al., 1991). After an extensive investigation of the vitrifying properties and embryotoxicity of a number of permeating cryoprotectants, Ali and Shelton (1993, in press) reported the successful vitrification of mouse embryos in vitrification solutions (VS) in which ethylene glycol was the major permeating cryoprotectant and using a procedure that was performed at room temperature $\left(25^{\circ} \mathrm{C}\right)$. The solutions were VS1 $(5.5 \mathrm{~mol}$ ethylene

*Present address: IVF Laboratory, Department of Obstetrics and Gynaecology, National University Hospital, Lower Kent Ridge Road, Singapore 0511.

Received 18 August 1992. glycol $\mathrm{l}^{-1}$ and $2.5 \mathrm{~mol}$ glycerol $\left.\mathrm{l}^{-1}\right)$, VSI1 (6.0 mol ethylene glycol $1^{-1}$ and $1.8 \mathrm{~mol}$ glycerol $\mathrm{l}^{-1}$ ) and VS14 (5.5 mol ethylene glycol $\mathrm{l}^{-1}$ and $1.0 \mathrm{~mol}$ sucrose $\left.\mathrm{l}^{-1}\right)$. The experiments reported here were conducted to assess the viability of day- 6 sheep embryos vitrified with VS1, VS11 and VS14.

\section{Materials and Methods}

\section{Superovulation of donor ewes}

The oestrous cycles of Merino ewes were synchronized by the insertion of intravaginal sponges containing $40 \mathrm{mg}$ flugestone acetate (Chrono-Gest, Intervet Australia Pty, Artarmon) for 12 days. Two days before removal of the sponges the ewes were superovulated by an i.m. injection of $12 \mathrm{mg}$ FSH and 500 iu of pregnant mares' serum gonadotrophin.

Immediately after removal of the sponges, the ewes were joined with harnessed rams. Fertilization was ensured by carrying out intrauterine insemination by laparoscopy $36-48 \mathrm{~h}$ after sponge removal.

\section{Collection of embryos}

The day- 6 sheep embryos (morulae, early blastocysts and blastocysts) were recovered from the donors under general anaesthesia (Pentothal, Bomac Laboratories, NSW). Each uterine horn was flushed by injection of Hepes-buffered medium 199 (Flow Laboratories, Irvine) containing $5 \%$ fetal calf serum through the fimbrial end of the oviduct and its collection 
through a Foley catheter (10FG $2.7 \mathrm{~mm}$; Norta, Malaysia) inserted anterior to the body of the uterus. The embryos were pooled in droplets of Hepes-buffered synthetic oviduct fluid (HSOF), containing $20 \%$ sheep serum, under paraffin oil. HSOF was synthetic oviduct fluid (SOF; Tervit et al., 1972) with $25 \mathrm{mmol}$ sodium Hepes $\mathrm{I}^{-1}$ and $4 \mathrm{mmol}$ sodium bicarbonate $\mathrm{l}^{-1}$. The pooled embryos were classified according to their stage of development and quality (Lindner and Wright, 1983) and those classified 'good' or 'excellent' were apportioned equally as appropriate for individual experiments.

\section{Exposure and vitrification of embryos}

Embryos were either exposed to VS in $100 \mu \mathrm{l}$ drops under paraffin oil at $25^{\circ} \mathrm{C}$ without subsequent vitrification or were vitrified after exposure. Embryos to be vitrified were exposed to the vitrification solution as described above and within the allotted exposure time for each experiment they were loaded into $0.25 \mathrm{ml}$ plastic insemination straws (IMV, L'Aigle). Each straw was prepared by filling it with VS and the plug end was heat sealed. With the VS-filled straw held horizontally, embryos (average of four per straw) were introduced with a fine pipette $35-40 \mathrm{~mm}$ from the open end of the straw which was then heat sealed. The sealed straw was then plunged horizontally into liquid nitrogen and held below the surface for 10-20 s (cooling rate approximately $2500^{\circ} \mathrm{C} \mathrm{min}^{-1}$; Rall, 1987). The straws containing vitrified embryos were stored in liquid nitrogen until use. Embryos that were not vitrified were not loaded into straws.

\section{Warming, dilution of VS and culture of embryos}

The embryos were warmed by directly immersing the vitrified straws in a water bath maintained at $25^{\circ} \mathrm{C}$ where they were held for 6-10 s (warming rate approximately $1000^{\circ} \mathrm{C}$ $\min ^{-1}$; Rall et al., 1986). The contents of the straw were emptied into $1.0 \mathrm{ml}$ of $1.0 \mathrm{~mol}$ sucrose $\mathrm{l}^{-1}$ and stirred gently to facilitate mixing of the two solutions. The embryos were tranferred to a $100 \mu \mathrm{l}$ drop of $1.0 \mathrm{~mol}$ sucrose $\mathrm{I}^{-1}$ under paraffin oil at $25^{\circ} \mathrm{C}$ for $10 \mathrm{~min}$ and finally into HSOF at $25^{\circ} \mathrm{C}$ for $5 \mathrm{~min}$ before use in various experiments. The cryoprotectants in the embryos that were exposed to cryoprotectant but not vitrified were removed in a similar manner. The embryos were finally transferred to SOF and cultured up to the blastocyst or hatching blastocyst stages at $37^{\circ} \mathrm{C}$ in an atmosphere of $5 \% \mathrm{CO}_{2}, 5 \% \mathrm{O}_{2}$ and $90 \%$ $\mathrm{N}_{2}$. Untreated day- 6 sheep embryos served as controls.

\section{Transfer of embryos}

Embryos vitrified with VS11 and VS14 were transferred after warming to recipient ewes in which the time of oestrus was controlled by the insertion of intravaginal sponges for 12 days and administration of 400 iu pregnant mares' serum gonadotrophin at the time of sponge withdrawal. Six days after oestrus, the ewes were sedated (Rompun, Bayer Australia Ltd, Botany) before transfer of embryos by laparoscopy. The exteriorized horn was punctured, and embryos (two per ewe) were introduced in a small amount of medium through a tom-cat catheter affixed to a $1 \mathrm{ml}$ syringe.
Pregnancy was determined by real time ultrasonography at 30-37 days after the transfer of embryos. The pregnancies were confirmed by surgery on day 50 of pregnancy or the ewes were allowed to proceed to term.

\section{Statistical analysis}

Comparisons between groups were done by $\chi^{2}$ analysis except for group sizes of less than 25 when Fisher's exact test was used.

\section{Results}

\section{Experiment 1: exposure or vitrification of day- 6 sheep embryos}

The various developmental stages of day- 6 sheep embryos were exposed to, or vitrified after exposure with, VS1, VS11 or VS14. Exposure was for 1-3 min (blastocysts were exposed for $1 \mathrm{~min}$; early blastocysts for $2 \mathrm{~min}$; morulae for $3 \mathrm{~min}$ ) with VS1 and VS11 and for 2 min with VS14. After warming and dilution the embryos were cultured.

VSI and VSII were not toxic to day- 6 embryos with the exception of VS1 to early blastocysts (Table 1). The survival of all developmental stages of day- 6 sheep embryos was significantly reduced by vitrification with VS1. The survival of morulae and early blastocysts was not affected by vitrification with VS11 but the survival of blastocysts was significantly reduced. All developmental stages of day- 6 sheep embryos were not affected ( 7 of 7) by vitrification with VS14 (not shown in Table 1).

\section{Experiment 2: vitrification of sheep blastocysts after partial equilibration}

In Expt 1 the survival of blastocysts was reduced by vitrification after exposure to VS11 for $1 \mathrm{~min}$. The aim of Expt 2 was to test other exposure times for blastocysts. Sheep blastocysts, expanded blastocysts and collapsed blastocysts were subjected to partial equilibration in VS11 for 1,3 or $5 \mathrm{~min}$ at $25^{\circ} \mathrm{C}$ and vitrified with VS11. The blastocysts were cultured after warming and dilution.

Although few embryos were used in the experiment, the results clearly suggest a decline in the rate of survival of sheep blastocysts and expanded blastocysts vitrified with VS1I when the duration of prior equilibration exceeded $1 \mathrm{~min}$. This effect was not evident with collapsed blastocysts (Table 2).

\section{Experiment 3: dehydration of day-6 sheep embryos before vitrification}

The survival of all the collapsed blastocysts, albeit a small number, in Expt 2 suggested that removal of the blastocoelic fluid might be beneficial to survival of vitrified embryos. In Expt 3 the embryos were first dehydrated by exposure to $1 \mathrm{~mol}$ sucrose $1^{-1}$ for $3 \mathrm{~min}$ at $25^{\circ} \mathrm{C}$. They were then partially equilibrated by exposure to VSII for 1, 3 or $5 \mathrm{~min}$, vitrified and treated as described above. 
Table 1. Percentage survival in vitro of day-6 sheep embryos exposed* to or vitrified with VSI and VSI1

\begin{tabular}{llllll}
\hline & & \multicolumn{4}{c}{ Stage of development } \\
\cline { 3 - 6 } $\begin{array}{l}\text { Vitrification } \\
\text { solution }\end{array}$ & Treatment & \multicolumn{4}{c}{$\begin{array}{c}\text { Early } \\
\text { blastocyst }\end{array}$} \\
\hline \multirow{2}{*}{ VS1 } & Blastocyst & Morula \\
& Control & $100 \quad(6)^{* *}$ & $96.4(28)$ & $59.0(39)$ \\
& Exposed & $100 \quad(4)$ & $64.3(14)^{\mathrm{a}}$ & $59.5(42)$ \\
VS11 & Vitrified & $11.1(9)^{\mathrm{b}}$ & $24.2(33)^{\mathrm{c}}$ & $26.8(41)^{\mathrm{b}}$ \\
& Control & $88.9(27)$ & $87.5(24)$ & $71.7(46)$ \\
& Exposed & $75.0(20)$ & $80.0(5)$ & $68.0(20)$ \\
& Vitrified & $11.5(26)^{\mathrm{c}}$ & $81.8(22)$ & $85.7(42)$ \\
\hline
\end{tabular}

*Durations of exposure were $1 \mathrm{~min}$ for blastocysts, $2 \mathrm{~min}$ for early blastocysts and $3 \mathrm{~min}$ for morulae. ${ }^{* *}$ Numbers in parentheses are numbers of embryos in the group. ${ }^{a} P<0.05$ compared with controls; ${ }^{b} P<0.005$ compared with controls; ${ }^{~} P<0.0001$ compared with controls.

Table 2. Percentage survival in vitro of day- 6 sheep blastocysts equilibrated for 1,3 or 5 min at $24^{\circ} \mathrm{C}$ and vitrified with VS11

\begin{tabular}{lcccc}
\hline & \multicolumn{5}{c}{ Duration (min) of equilibration with VS11 } \\
\cline { 2 - 5 } $\begin{array}{l}\text { Stage of } \\
\text { development }\end{array}$ & $\begin{array}{c}\text { Untreated } \\
\text { controls }\end{array}$ & 1 & 3 & 5 \\
\hline Blastocysts & $87.5(8)^{*}$ & $50.0(8)$ & $0(8)$ & $12.5(8)^{\mathrm{a}}$ \\
Expanded blastocysts & $100 \quad(2)$ & $50.0(2)$ & $0(8)$ & 0 \\
Collapsed blastocysts & - & - & $100(2)$ & $100(2)$ \\
\hline
\end{tabular}

${ }^{*}$ Numbers in parentheses are numbers of embryos in the group. ${ }^{a} P<0.05$ compared with controls.

After warming and culture, only one of 11 blastocysts survived in vitro. No expanded blastocysts (of 10), early blastocysts (of 16) or morulae (of 13) survived.

\section{Experiment 4: vitrification of day-6 sheep embryos after exposure to dilutions of VS11}

Sheep embryos in earlier experiments showed quite good survival in vitro after vitrification in VS11. However, observations on survival of embryos transferred to recipients after vitrification in VS1I were less encouraging. The possibility that a more gradual introduction to the high osmolarity of VS11 might be less traumatic was examined by exposing day- 6 embryos for $5 \mathrm{~min}$ in $20,30,40$ or $50 \% \mathrm{VS} 11$ at $25^{\circ} \mathrm{C}$, and then vitrifying with $100 \%$ VS11 (two-step method). The embryos were cultured after warming and VS dilution with sucrose.

There were no significant effects of exposure to any dilution of VSI1 before vitrification on the survival of individual developmental stages (Table 3). When all the developmental stages were grouped together the survival of the embryos that were exposed to $20 \%$ and $50 \%$ VS11 for $5 \mathrm{~min}$ and then vitrified with $100 \%$ VS11 was significantly reduced $(P<0.05$ and $<0.005$, respectively). The survival of embryos was not affected when they were vitrified after exposure to $30 \%$ or $40 \%$ VS11. The survival rate in the latter two groups was $88.2 \%$ and $85.7 \%$, respectively.

\section{Experiment 5: viability of vitrified day-6 sheep embryos when} transferred to surrogates

The viability in vivo of embryos vitrified in VSII and VSI4 was tested by transferring vitrified day- 6 sheep embryos, after warming, to recipient ewes. In the first part of the experiment, embryos were vitrified in VS11 after direct exposure to $100 \%$ VSI1 ( $1 \mathrm{~min}$ for blastocysts, $2 \mathrm{~min}$ for early blastocysts and $3 \mathrm{~min}$ for morulae) in one step. In the second part, embryos were vitrified after exposure to $30 \%$ VSII for $5 \mathrm{~min}$ and to $100 \%$ VS11 for $1.5 \mathrm{~min}$. In addition in this part of the experiment a small number of embryos were vitrified after 2 min exposure to VS14 in one step. The VS in embryos vitrified with VS11 (one-step) was removed by sucrose dilution or directly with HSOF medium (without sucrose dilution). In all other treatments, VS was removed by sucrose dilution.

The viability of embryos after transfer to recipients was poor when day- 6 embryos were vitrified in one step with VSII and was not affected by the method of dilution (Table 4). 
Table 3. Percentage survival in vitro of day- 6 sheep embryos equilibrated with various dilutions of VS1 1 at $25^{\circ} \mathrm{C}$ before vitrification with VS11

\begin{tabular}{|c|c|c|c|c|c|}
\hline \multirow[b]{2}{*}{$\begin{array}{l}\text { Stage of } \\
\text { development }\end{array}$} & \multicolumn{5}{|c|}{ Percentage dilution of VS11 for equilibration } \\
\hline & $\begin{array}{l}\text { Untreated } \\
\text { controls }\end{array}$ & 20 & 30 & 40 & 50 \\
\hline Expanded blastocysts & $88.9(9)^{*}$ & $55.6(9)$ & $81.8(11)$ & $66.7(9)$ & $33.3 \quad(3)$ \\
\hline Blastocysts & $100 \quad(12)$ & $100 \quad(7)$ & $90.9(11)$ & $100 \quad(10)$ & $66.7 \quad(3)$ \\
\hline Early blastocysts & $100 \quad(6)$ & $33.3(3)$ & $88.9(9)$ & $100 \quad(4)$ & $83.3(6)$ \\
\hline Morulae & $100 \quad(5)$ & $100 \quad(3)$ & $100 \quad(3)$ & 80.0 & $40.0 \quad(5)$ \\
\hline Total & $96.9(32)$ & $72.7(22)^{a}$ & $88.2(34)$ & $85.7(28)$ & $58.8(17)^{b}$ \\
\hline
\end{tabular}

${ }^{*}$ Numbers in parentheses are numbers of embryos in group. ${ }^{a} P<0.05$ compared with untreated controls; ${ }^{b} P<0.005$ compared with untreated controls.

Table 4. Survival of day-6 sheep embryos vitrified with VS11 and VS14 when transferred to recipient ewes

\begin{tabular}{|c|c|c|c|c|c|}
\hline \multirow{2}{*}{$\begin{array}{l}\text { Vitrification } \\
\text { solution } \\
\text { (method) }\end{array}$} & \multirow{2}{*}{$\begin{array}{l}\text { Developmental } \\
\text { stage of } \\
\text { embryos }\end{array}$} & \multicolumn{2}{|c|}{ Number of embryos } & \multicolumn{2}{|c|}{ Number of ewes } \\
\hline & & Transferred & Survived (\%) & Recipient & Pregnant (\%) \\
\hline $\begin{array}{l}\text { VS11 } \\
\text { (one-step) }\end{array}$ & $\begin{array}{l}\text { Blastocysts } \\
\text { Early blastocysts } \\
\text { Morulae }\end{array}$ & $\begin{array}{l}30 \\
60 \\
68\end{array}$ & $\begin{array}{rr}0 & \\
1 & (1.7) \\
7 & (10.3)\end{array}$ & $\begin{array}{l}12 \\
33 \\
34\end{array}$ & $\begin{array}{lr}0 & \\
1 & (3.0) \\
7 & (20.6)\end{array}$ \\
\hline $\begin{array}{l}\text { VSII } \\
\text { (two-step) }^{* *}\end{array}$ & $\begin{array}{l}\text { Expanded blastocysts } \\
\text { Blastocysts } \\
\text { Early blastocysts } \\
\text { Morulae }\end{array}$ & $\begin{array}{r}4 \\
29 \\
10 \\
29\end{array}$ & $\begin{aligned} 2 & (50.0) \\
18 & (62.1) \\
1 & (10.0) \\
16 & (55.2)\end{aligned}$ & $\begin{array}{r}2 \\
14 \\
5 \\
14\end{array}$ & $\begin{aligned} 1 & (50.0) \\
11 & (78.6) \\
1 & (20.0) \\
11 & (78.6)\end{aligned}$ \\
\hline $\begin{array}{l}\text { VSI4 } \\
\text { (one-step) }^{* *}\end{array}$ & $\begin{array}{l}\text { Expanded blastocysts } \\
\text { Blastocysts } \\
\text { Morulae }\end{array}$ & $\begin{array}{l}4 \\
4 \\
2\end{array}$ & $\begin{array}{l}0 \\
4(100.0) \\
1 \quad(50.0)\end{array}$ & $\begin{array}{l}2 \\
2 \\
1\end{array}$ & $\begin{array}{l}0 \\
2(100.0) \\
1(100.0)\end{array}$ \\
\hline
\end{tabular}

*Pooled results for dilution of VS with and without sucrose $\left(\mathrm{I}\right.$ mol $\left.\mathrm{I}^{-1}\right) .{ }^{* *}$ Diluted with sucrose (I mol $\left.1 \mathrm{l}\right)$.

The embryo survival and pregnancy rates for the different developmental stages that were exposed to $30 \%$ VS11 for $5 \mathrm{~min}$ and then vitrified with $100 \%$ VSII (two-step) were: morulae $55 \%$ and $79 \%$, blastocysts $62 \%$ and $79 \%$, early blastocysts $10 \%$ and $20 \%$ and expanded blastocysts $50 \%$ and $50 \%$, respectively.

The embryo survival and pregnancy rates of the small number of sheep morulae and blastocysts that were vitrified with VS14 were $50 \%$ and $100 \%$, and $100 \%$ and $100 \%$, respectively. None of the four expanded blastocysts that were vitrified with VSI4 survived in vivo.

\section{Discussion}

Studies on the vitrification of mouse embryos (Ali and Shelton, 1993) indicated that complete equilibration with cryoprotectant was unnecessary. It was suggested that in addition to cryoprotective action, a major role of the VS was to induce dehydration in embryos, thereby greatly increasing the intracellular solute concentrations to allow intracellular glass formation during cooling. The VS provides extracellular protection by forming extracellular glass during cooling. The same appears to be true for day- 6 sheep embryos.

Day-6 sheep embryos were quite tolerant to VS1 but did not survive vitrification in this solution. No further investigations were therefore performed with VS1. Sheep early blastocysts and morulae can be vitrified with VS11 with no loss of viability in vitro. Previous studies (Ali, 1992; Ali and Shelton, 1993) performed on mouse preimplantation embryos suggested that the toxicity of VSI and VSII was probably positively related to the amount of glycerol present in the VS. VS11 has less gylcerol $\left(1.8 \mathrm{~mol} \mathrm{l}^{-1}\right)$ than VS1 $\left(2.5 \mathrm{~mol} \mathrm{l}^{-1}\right)$ and is less toxic. The studies in Expt 1 showed little difference in toxicity between VS1 and VSI1 when day- 6 sheep embryos were exposed to these solutions for 1-3 min, but there was a significant difference in survival after vitrification. It is not clear whether this is due to enhanced embryotoxicity of VSI under conditions of vitrification or to inadequate cryoprotection by 
VS1. Survival of blastocysts was severely reduced by vitrification. Valdez et al. (1990) reported a similar sensitivity of mouse blastocysts to vitrification. In our experiments there was no deleterious effect on early sheep blastocysts.

Experiments conducted to determine whether the lower viability of sheep blastocysts vitrified with VSII was related to insufficient equilibration revealed that equilibration for $3 \mathrm{~min}$ or more was detrimental to their survival. However, the survival in vitro of collapsed blastocysts vitrified after equilibration for 3-5 min with VS11 suggested that the prior removal of the blastocoelic fluid could be beneficial and could enhance the survival of the vitrified blastocyst. Experiments to test this suggestion proved otherwise when the blastocoelic fluid was removed by challenging the blastocyst with 1 mol sucrose $\mathrm{l}^{-1}$. Day- 6 embryos of all developmental stages did not survive when they were subjected to dehydration with sucrose after which they were equilibrated for 1,3 or $5 \mathrm{~min}$ and then vitrified with VS11. It is, however, obvious that the turgidity of the blastocysts is somehow related to higher sensitivity to the VS, possibly because they suffer greater osmotic trauma and damage than do non-turgid blastocysts when challenged with the VS. Turgid blastocysts may be more vulnerable than collapsed blastocysts because sudden challenge with a highly concentrated permeating solution may result in abrupt ultrarapid movement of a relatively large volume of fluid across the cell membrane. This may result in damage.

The reason for the poor survival in vivo of embryos vitrified in one step compared with the survival in vitro is not clear. Studies (Ali, 1992) have shown that viability of sheep morulae in vitro was not reduced by exposure to VS11 until $20 \mathrm{~min}$ at $25^{\circ} \mathrm{C}$. Studies on volume changes in the embryo following exposure to VS (Ali, 1992) also appear to confirm this suggestion. The data presented here and elsewhere (Ali, 1992; Ali and Shelton, 1993) suggest that, in spite of survival in vitro of embryos vitrified in one step, the number of blastomeres that survive vitrification are insufficient or mainly consisted of, or gave rise to, trophoblastic cells, rendering the embryo incapable of establishing a viable pregnancy. Indeed the number of cells in vitrified (one-step) early sheep blastocysts $(n=5$; mean $=59.8 ; \mathrm{SEM}=13.10$ ) that were cultured for $48 \mathrm{~h}$ after warming were significantly lower $(P<0.005)$ than those in untreated early blastocysts that were similarly cultured $(n=4$; mean $=138.0 ;$ SEM $=11.95$ ). It was concluded that a significant number of blastomeres of day- 6 sheep embryos were irreversibly damaged during the one-step vitrification procedure, possibly owing to excessive osmotic stress, with the result that subsequent viability was reduced in vivo but not in vitro.

The problem of osmotic damage to the blastomeres of day- 6 sheep embryos when exposed to VS11 (which is $7.8 \mathrm{~mol} \mathrm{l}^{-1}$ ) was overcome by initially exposing the embryos to one of the various dilutions of VS11 ranging from 20 to $50 \%$ before vitrification with the undiluted (100\%) VS11. Initial exposure to 30 and $40 \%$ VS11 followed by vitrification with the undiluted VS1I resulted in the highest in vitro survival rates which were comparable to that of untreated embryos. It is suggested that this regimen provided less harmful osmotic steps than initial treatment with 20 or $50 \%$ VS11.

Day- 6 sheep embryos vitrified by the two-step procedure, particularly morulae and blastocysts, resulted in high embryo survival and pregnancy rates when transferred to recipients.
The viability of early sheep blastocysts in vivo was poor with a $10 \%$ embryo survival and $20 \%$ pregnancy rate. However, the number of embryos at this stage was too small to be conclusive. Experiments with a larger sample size would be needed to show any real effect of developmental stage.

Survival rates of 30 to $60 \%$ have been reported after transfer of embryos frozen-thawed by conventional methods with a variety of cryoprotectants (Willadsen, 1977; Tervit and Goold, 1984; Heyman et al., 1987). There have been few reports of successful vitrification of sheep embryos. McGinnis and Youngs (1990) reported survival of blastocysts in vitro after vitrification and Schiewe et al. (1991) reported two live offspring from transfer of seven embryos vitrified in $6.5 \mathrm{~mol}$ glycerol $\mathrm{l}^{-1}$ and $6 \%$ BSA. Szell et al. (1990) obtained $11 \%$ (4 of 35) in vivo survival of morulae and $32 \%$ (6 of 19) for blastocysts and hatching blastocysts vitrified in a medium consisting of $25 \%$ glycerol and $25 \%$ propylene glycol after exposure at $4-12^{\circ} \mathrm{C}$. Thus, results reported here, $62 \%$ ( 18 of 29 ) for blastocysts and $51 \%$ (37 of 72 ) for all developmental stages of day- 6 sheep embryos, are similar to those reported from conventional freeze-thaw procedures, and superior to those in earlier reports on vitrification. Furthermore, exposure to the vitrification medium was at $25^{\circ} \mathrm{C}$. It is worth noting that, although there was no concurrent comparison of freeze-thaw procedures in the experiment reported here, in a previous experiment in this laboratory (Shelton, 1992), survival of embryos frozen in $1.5 \mathrm{~mol}$ ethylene glycol or glycerol $\mathrm{I}^{-1}$ and transferred one per recipient was $45.2 \%$. The data presented here and elsewhere (Ali and Shelton 1993, in press) strongly suggest that the use of ethylene glycol as the major permeating cryoprotectant in the vitrification medium is the reason for the greater success rate. Tervit and Goold (1984) and Heyman et al. (1987) remarked on the advantages of ethylene glycol in conventional procedures.

The results suggest that VS14 can be used to vitrify day- 6 sheep embryos by a one-step procedure with little loss of viability. VS14 consists of $5.5 \mathrm{~mol}$ ethylene glycol $\mathrm{I}^{-1}$ and $1.0 \mathrm{~mol}$ sucrose $\mathrm{I}^{-1}$, whereas VS11 consists of $6.0 \mathrm{~mol}$ ethylene glycol $\mathrm{I}^{-1}$ and $1.8 \mathrm{~mol}$ glycerol $\mathrm{l}^{-1}$. Neither $5.5 \mathrm{~mol}$ ethylene glycol nor $1.0 \mathrm{~mol}$ sucrose $\mathrm{l}^{-1}$ will vitrify on its own, but the combination will vitrify. Furthermore these concentrations of ethylene glycol and sucrose alone or in combination are nontoxic to embryos (Ali, 1992; Szell and Shelton, 1986). VS14 is potentially a very good vitrification agent for mammalian embryos and warrants further investigation.

The authors thank B. Barancewicz and S. Horton for their assistance during sheep embryo recovery and transfer procedures. We are grateful to $\mathrm{G}$. Hughes for his care of experimental animals.

\section{References}

Ali J (1992) Factors Affecting Ultrarapid Vitrification and Cryopreservation of Embryos PhD Thesis, Australian National University, Canberra

Ali J and Shelton JN (1993) Vitrification of preimplantation stages of the mouse embryo Joumal of Reproduction and Fertility 98 459-465

Ali $J$ and Shelton JN The design of vitrification solutions for the cryopreservation of embryos Journal of Reproduction and Fertility (in press)

Heyman Y, Vincent C, Garnier V and Cognie Y (1987) Transfer of frozenthawed embryos in sheep Veterinary Record 120 83-85

Lindner GM and Wright RW (1983) Bovine embryo morphology and evaluation Theriogenology 20 407-416 
Luyet B (1937) The vitrification of organic colloids and of protoplasm Biodynamica 1 I-14

McGinnis LK and Youngs CR (1990) Vitrification of ovine embryos Theriogenology 33287 (Abstract)

Rall WF (1987) Factors affecting the survival of mouse embryos preserved by vitrification Cryobiology 24 387-402

Rall WF, Meyer TK and Leibo SP (1986) Effect of warming conditions on the survival of mouse embryos cryopreserved and diluted by a one-step straw procedure Theriogenology 25186 (Abstract)

Schiewe MC, Rall WF, Stuart LD and Wildt DE (1991) Analysis of cryoprotectant cooling rate and in situ dilution using conventional freezing or vitrification for cryopreserving sheep embryos Theriogenology 36 279-293

Shelton JN (1992) Factors affecting viability of fresh and frozen-thawed sheep demi-embryos Theriogenology 37 713-721

Szell A and Shelton JN (1986) Sucrose dilution of glycerol from mouse embryos frozen rapidly in liquid nitrogen vapour Journal of Reproduction and Fertility 76 401-408

Szell A, Zhang J and Hudson R (1990) Rapid cryopreservation of sheep embryos by direct transfer into liquid nitrogen vapour at $-180^{\circ} \mathrm{C}$ Reproduction Fertility and Development 2 613-618
Tervit HR and Goold PG (1984) Deep-freezing sheep embryos Theriogenology 21268 (Abstract)

Tervit HR, Whittingham DG and Rowson LEA (1972) Successful culture in vitro of sheep and cattle ova Journal of Reproduction and Fertility 30 493-497

Valdez CA, Abas Mazni O, Takahashi Y, Hishinuma M and Kanagawa H (1990) Effects of equilibration time, precooling and developmental stage on the survival of mouse embryos cryopreserved by vitrification Theriogenology 33 $627-636$

Whittingham DG, Leibo SP and Mazur P (1972) Survival of mouse embryos frozen to $-196^{\circ} \mathrm{C}$ and $-269^{\circ} \mathrm{C}$ Science $178411-414$

Willadsen SM (1977) Factors affecting the survival of sheep embryos during deep-freezing and thawing. In The Freezing of Mammalian Embryos, Ciba Foundation Symposium 52, pp 175-202 Eds K. Elliot and J. Whelan. Elsevier/ North Holland, Amsterdam

Willadsen SM, Polge C, Rowson LEA and Moor RM (1976) Deep-freezing of sheep embryos Journal of Reproduction and Fertility 46 151-154 